\title{
Complement or Compensate? Interaction of IQ and Job Experience with Emotional Intelligence in Marketing Exchanges
}

\author{
Andreas Zehetner \\ University of Applied Sciences Upper Austria \\ Daniela Zehetner \\ Simon Kuznets Kharkiv University of Economics
}

\begin{abstract}
Although the impact of emotional intelligence (EI), cognitive intelligence (IQ) and experiential or practical intelligence (Epstein 1993) have been discussed in various contexts and for many years, its interaction, compound or compensatory effects in predicting performance in marketing exchanges remain unclear. This paper elaborates if and how EI, IQ, and job experience (as a proxy for experiential intelligence) compensate or complement each other in business negotiations. EI and IQ are estimated through standardized tests. The INSBAT Test (IQ) and the trait emotional intelligence questionnaire (TEIQUE) are employed. The sample is composed of 154 graduate students of a business programme with different levels of job experience. Their negotiation performance is measured through an experimental negotiation role-play. Data is analysed from both the seller's and the buyer's perspective.
\end{abstract}

Keywords: Negotiation, Emotional Intelligence, Sales People Selection, Sales Performance, Marketing Exchanges, Cognitive Intelligence, Job Experience, Sales Management

\section{INTRODUCTION}

EI and IQ are two dimensions that are consulted to assess a sales person's capabilities to fulfil his/her later job in the best possible way. Dual process theories (Cacioppo \& Gardner 1999; Evans 2003) advocate that cognitive as well as emotional components influence performance. Lawler (2001), in his affect theory of social exchange, states that EI plays a role in performing exchange processes. Several studies have researched the effect of emotions and cognitive abilities, and experience, in buyer-seller constellations, marketing exchanges, and relationship development (e.g. Andersen \& Kumar 2006; Kidwell 2011).

When testing job candidates, employers tend to select people that accumulate highest scores on all measured dimensions, and, ideally, they should bring along vast job experience. A weakness in one dimension is often treated as a knockout criterion, and is not checked against maybe high levels in another dimension. Is this the way to find the best performing employee? This paper is about to question this believe. Accordingly, the main research question of this paper is put as: Are there complementary or compensatory effects of EI, IQ, and job experience in their influence on job performance? 


\section{EMOTIONAL INTELLIGENCE, COGNITIVE INTELLIGENCE, AND JOB EXPERIENCE}

Bar-On (2003) found that EI is considered to be a better predictor of job success than IQ. Goleman (1995) suggested that, for personal success, EI is an entering point. Both agree that EI plays an important role in a carrier success; it helps to socialize, empathize, and, finally, negotiate, which is essential for a growing globalized economy. O'Boyle et al. (2011) found in a meta-analysis that EI supports individual performance in work-related activities including leadership and teamwork projects, while IQ tends to support work activities related to individual cognitive assignments and academic tests. Verbeke et al. (2008) compared influences of IQ and social competencies on sales people's performance. Their findings indicate a moderating effect of social competencies on the IQ - performance relationship such as high levels of social competencies lead to a much stronger influence of IQ on performance and vice versa. Job experience is the proportion of experience which is associated with a person's professional activities (Quiñones, Ford, J. Kevin, \& Teachout 1995). Becker's (1962) human capital theory posits that more experienced employees perform better than inexperienced ones. Experiential learning theory and practical intelligence literature (Epstein 1993) emphasizes the central role of experience learning and assumes a positive relationship of job experience and performance (Kolb, Boyatzis, \& Mainemelis 2011).

\section{NEGOTIATION AND NEGOTIATION PERFORMANCE}

Pruitt (2013, p. xi) defines negotiation 'as a form of decision making in which two or more parties talk with one another in an effort to resolve their opposing interests'. When heading into a negotiation, parties have different interests and objectives concerning the outcome of the negotiation (Thompson, Wang \& Gunia 2010). Many factors have been found to be influential on negotiation outcome or moderating negotiators' performance. Contemporary research pays more attention to the emotional competences of negotiators and their contribution to a negotiation outcome. Several studies show that positive emotions contribute to a better decision making process, facilitating problem solving thinking and creative ideas (Carnevale \& Isen 1986), win/win settlements (Hollingshead \& Carnevale 1990), satisfaction of an opponent (Forgas 1998), and establishment of relationship (Lawler, Thye \& Yoon 2000). Negotiation performance here is defined as the quantifiable result of a negotiation (buying/selling) about the price of a product and its accompanying services in a single transaction.

\section{HYPOTHESIS DEVELOPMENT}

In the following section, hypotheses will be developed to reveal compensation or complementary effects of EI, IQ, and job experience, respectively.

\section{Interaction of EI and IQ}

Cognitive intelligence (IQ) is a general mental capability that involves the ability to reason, plan, solve problems, think abstractly, and comprehend complex ideas. It is easy to assume that successful people are equipped with a higher cognitive intelligence than the average of the population, but IQ is not the sole driver of success or performance. IQ as well as EI have an influence on negotiation performance, and they are not opposite, but rather separate competences (Block 1995). Akers and Porter (2003) argue that there is only a low influence of IQ on performance, while the remainder depends on other factors, which may be influenced by EI. Dual process theories suggest that the performance of a person with a lower level of IQ might be positively influenced or even compensated by a higher level of other competencies (Cacioppo and Gardner 1999). Consequently, we state that IQ moderates the effect of EI on negotiation performance in a way that with lower levels of IQ, EI has a stronger effect on negotiation outcome than with higher levels of IQ (H1). 


\section{Interaction of EI and Job Experience}

Bartkus et al. (1989, p. 15) distinguish between inexperienced and experienced sales people: 'It is possible that inexperienced salespeople perform well by working harder while experienced salespeople perform well by working smarter'. During the years of experience, sales people learn how to use their abilities in the most effective way. It can be assumed that the more experienced a sales person is the more can he/she exploit his/her EI and IQ to perform better. A complementary effect is hypothesized in a way that job experience moderates the effect of EI on negotiation performance such as the effect of EI on performance is stronger with experienced than with less experienced negotiators $(\mathrm{H} 2)$.

\section{Controlling for Gender Effects}

Gender differences in the context of negotiations have been a topic over the past years (e.g. Stuhlmacher and Walters 1999). It was suggested that men tend to rely more on logic and behave rationally, while women rely on intuition and emotions. In addition, men are expected to emphasize objective facts and apply objective reasoning, while women focus mainly on relationships (Gilligan 1982). This means that women tent to practice the use of emotional abilities more and therefor know better how to use them in an effective way. As this might also materialize in negotiation performance, the effects of emotional intelligence would be affecting negotiation outcomes more for female negotiators. We state that gender influences the effect of EI on negotiation performance in a way that the effect of EI on negotiation performance is stronger with female than with male negotiators (H3).

\section{RESEARCH DESIGN AND MEASURES}

For this study, respondents were selected among full time and part time students of an Austrian graduate business programme. Data were gathered through an experimental role-play, followed by questionnaires for EI and demographics and completed by data for IQ gathered from the university entrance exams. 154 graduate business students, 93 female, 61 male took part in the experiment. Two games with multiple variables to negotiate about were designed, one of which was to sell/buy a welding aggregate and the other one comprised a business service (a sales training). The bargaining variables included the price of the product/service plus various service components, like shipping, customization, warranty etc. Performance was computed by calculating the outcome (the negotiated price and three additional bargaining variables against the maximum possible gain in both games. Each student was tested two times, one time as a seller, and one time as a buyer, with different partners each time to avoid habituation effects. Cognitive intelligence was assessed by the INSBAT Test (Arendasy et al. 2012). Emotional intelligence was assessed with the trait emotional intelligence questionnaire (TEIQue SF; Petrides 2010). The instrument does not require 'right' or 'wrong' answers and therefore is applicable in multiple contextual settings. Gender as well as job experience in years and month were provided by the students.

\section{DATA ANALYSIS}

To test the hypothesized relationships, split-group regression analyses were performed. This traditional method was selected in accordance with Cohen \&Cohen (1983), Stone \& Hollenbeck (1989), and Aiken \& West (1991), as it was of explicit interest, how low and high groups of the interacting variables differ in their power to explain performance. 
TABLE 1

DATASET SPLIT GROUP ANALYSIS

Coefficients $^{\mathrm{a}, \mathrm{b}}$

\begin{tabular}{|c|c|c|c|c|c|c|c|}
\hline IQ & & & B & Std. Error & Beta & $\mathrm{t}$ & Sig. \\
\hline \multirow[t]{3}{*}{ IQ low } & \multirow[t]{3}{*}{1} & GENDER & .013 & .070 & .019 & .183 & .856 \\
\hline & & EXPERIENCE & -.244 & .105 & -.257 & -2.312 & .023 \\
\hline & & EI & .294 & .099 & .327 & 2.968 & .004 \\
\hline \multirow[t]{3}{*}{ IQ high } & \multirow[t]{3}{*}{1} & GENDER & .036 & .078 & .054 & .463 & .645 \\
\hline & & EXPERIENCE & .269 & .131 & .248 & 2.054 & .044 \\
\hline & & EI & .050 & .132 & .045 & .377 & .708 \\
\hline
\end{tabular}

a. Dependent Variable: SUM BUY AND SELL

b. Linear Regression through the Origin

Coefficients $^{\mathrm{a}, \mathrm{b}}$

\begin{tabular}{|c|c|c|c|c|c|c|c|}
\hline \multirow{2}{*}{$\frac{\text { EXPERIENCE }}{\text { EXPERIENCE low }}$} & \multicolumn{2}{|c|}{ Model } & \multirow{2}{*}{$\begin{array}{l}\mathrm{B} \\
-.019\end{array}$} & \multicolumn{2}{|c|}{ Std. Error Beta } & \multirow{2}{*}{$\frac{t}{-.206}$} & \multirow{2}{*}{$\frac{\text { Sig. }}{.837}$} \\
\hline & 1 & GENDER & & .093 & -.025 & & \\
\hline & & IQ & -.022 & .120 & -.023 & -.188 & .852 \\
\hline & & EI & .307 & .123 & .304 & 2.501 & .015 \\
\hline \multirow[t]{3}{*}{ EXPERIENCE high } & 1 & GENDER & .075 & .072 & .123 & 1.033 & .305 \\
\hline & & IQ & .171 & .122 & .165 & 1.410 & .163 \\
\hline & & EI & -.048 & .132 & -.043 & -.361 & .719 \\
\hline
\end{tabular}

a. Dependent Variable: SUM BUY AND SELL

b. Linear Regression through the Origin

Coefficients $^{\mathrm{a}, \mathrm{b}}$

\begin{tabular}{|c|c|c|c|c|c|c|}
\hline GENDER & Model & B & Std. Error & Beta & $\mathrm{t}$ & Sig. \\
\hline \multirow[t]{3}{*}{ Female } & 1 & EXPERIENCE-.070 & .158 & -.048 & -.446 & .657 \\
\hline & & -.045 & .109 & -.043 & -.410 & .683 \\
\hline & & 190 & .111 & .183 & 1.711 & .090 \\
\hline \multirow[t]{3}{*}{ Male } & 1 & EXPERIENCE.079 & .096 & .112 & .827 & .411 \\
\hline & & 270 & .127 & .270 & 2.118 & .039 \\
\hline & & 131 & .122 & .144 & 1.079 & .285 \\
\hline
\end{tabular}

a. Dependent Variable: SUM BUY AND SELL

b. Linear Regression through the Origin

H1 predicted that lower IQ increases the effect of EI on negotiation outcome. Regression was performed with a IQ high and a IQ low group, split at the median. Results show that only with lower levels of IQ, EI has a significant effect on negotiation performance $(\beta=.327 ; t=2.968 ; p=.004)$. For higher levels of IQ, no significant effect was found. To reveal effects of various combinations of EI and IQ on negotiation performance of buyers and sellers, all possible combinations of EI and IQ were subjected to an univariate ANOVA $(\mathrm{F}(3,147)=3.866, \mathrm{p}=.011)$ and a Tukey HSD post-hoc test, accordingly. The analysis revealed that, not unexpectedly, the combination of low IQ and low EI (mean = .838) led to worst negotiation performance. However, the combination of high EI and high IQ (mean = .925) did also not provide the best mean values of performance. Those were achieved by combinations of either high EI and low IQ (mean = 1.058), or low EI and high IQ (1.016), which was surprising. 


\section{FIGURE 1 \\ NEGOTIATION PERFORMANCE ON VARIOUS COMBINATIONS OF HIGH/LOW IQ AND EI}

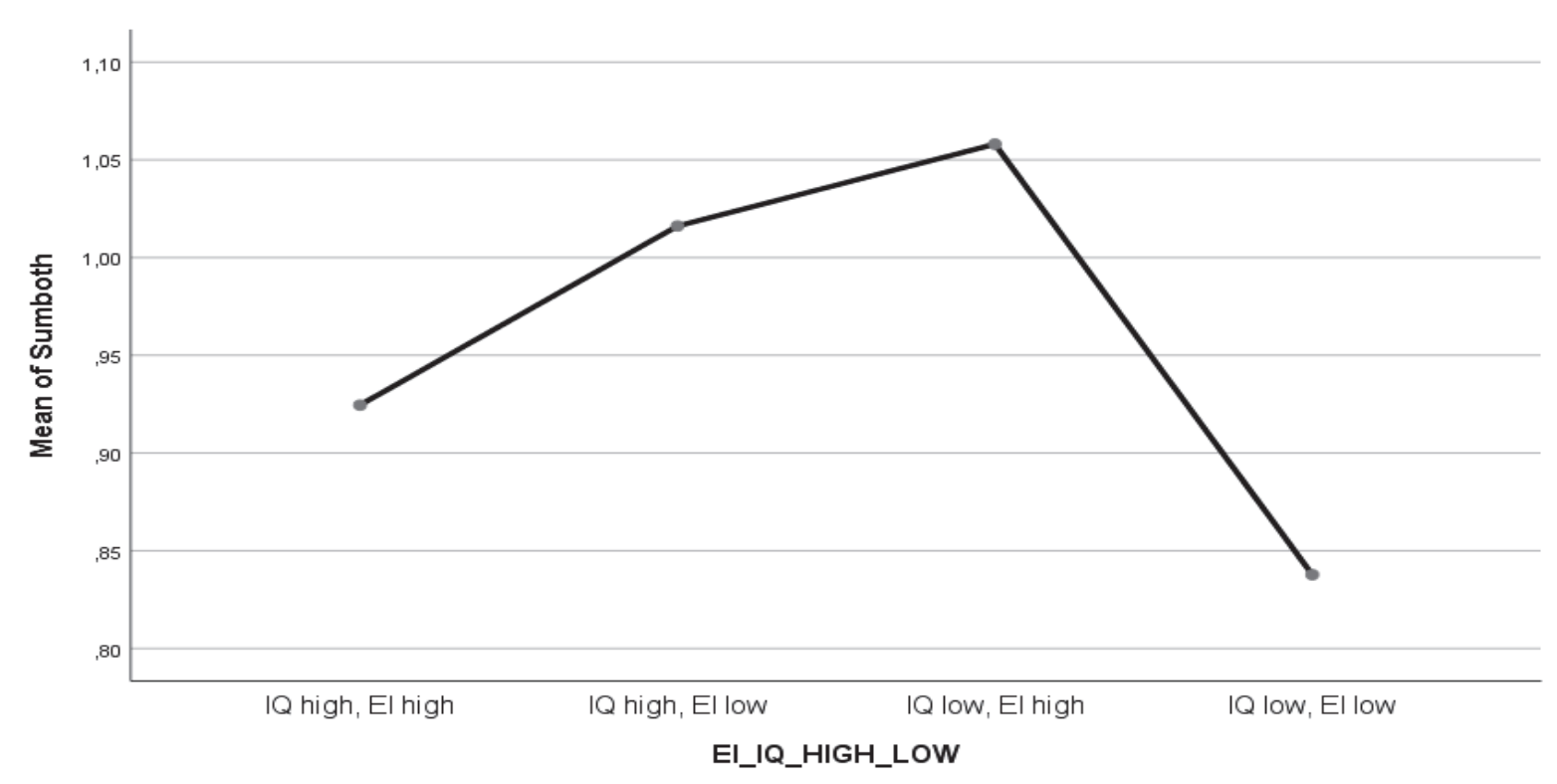

To investigate job experience effects $(\mathrm{H} 2)$, the dataset was split into two groups at the experience median. Regression of EI on negotiation performance was computed for both groups, controlling for gender, and IQ. Results show that with a low level of job experience, EI significantly relates to negotiation performance $(\beta=.304 ; \mathrm{t}=2.501 ; \mathrm{p}=.015)$. H2 is rejected as it assumes a positive correlation of these variables.

H3 tests gender effects on the EI and negotiation performance relationship. Results show, after controlling for IQ and experience, that for female negotiators the effect of EI on negotiation performance is stronger, although marginally not significant $(\beta=.183 ; \mathrm{t}=1.711 ; \mathrm{p}=.090)$. Interestingly, a (not hypothesized) significant effect of IQ for the group of male negotiators has been found $(\beta=.270 ; t=$ $2.118 ; \mathrm{p}=.039)$. As this was interesting, additional analyses were performed for negotiation outcomes of buyers and those of sellers, which revealed that women as buyers use their EI to achieve performance $(\beta=.283 ; \mathrm{t}=2.714 ; \mathrm{p}=.008)$, whilst men as sellers use their IQ $(\beta=.261 ; \mathrm{t}=2.069 ; \mathrm{p}=.043)$.

\section{DISCUSSION AND THEORETICAL IMPLICATIONS}

This study has found several confirmations but also contradictions to existing literature. First, it supports dual process theories, which suggest an interplay of cognitive as well as emotional components to affect performance. However, there was no linear positive influence found of both of these traits combined. At lower levels of IQ, EI gains more influence on negotiation performance. This is in contrast to e.g. Kidwells (2011) study who found that the correlation between EI and sales performance is positive at higher levels of cognitive ability, and also to Verbeke's (2008) findings that high levels of social competencies lead to a stronger influence of IQ on performance.

Secondly, the finding that best performance occurs at high/low combinations of EI/IQ and vice versa, but not at high/high combinations of both, supports arguments of 'too-much-of-a good thing'-effects in management (e.g. Pierce and Aguinis 2013).

Thirdly, job experience seems to compensate for EI in explaining negotiation performance. Less experienced people can better make use of their emotional competencies to reach their achieved goals. This adds a different perspective to Bartkus et al's. (1989) theoretical argument that 'inexperienced 
salespeople perform well by working harder while experienced salespeople perform well by working smarter' (p.15). EI compensates for a smaller amount of experience.

Lastly, with respect to the moderating effect of gender on the relationship between EI and negotiation outcome, for male negotiators IQ is dominant in explaining the variance of negotiation performance, whereas it is EI for female test persons. This confirms Gillians' (1982) theoretical arguments on gender differences.

\section{CONCLUSIONS}

The findings shed light on the relationship between EI, IQ and negotiation performance as well as on interaction effects with several variables. It can be concluded that negotiation performance is influenced by EI, but several interaction effects do play a role, that these interaction effects are not strictly positive and that there are differences in those effects for buyers and sellers. Suspected deficiencies in e.g. IQ, or experience, are compensated by higher contributions of EI to performance.

For practitioners, the findings may help to better grasp and higher value the impact of EI and IQ for sales people recruiting. HR managers and sales managers should put more emphasis on the constructs of EI and IQ in their selection procedures, selecting and training of salesforce. Additionally, effects of experience, gender, and IQ, and the interaction of those play a role in selecting the right person for the right job. A company can use assessment centres to determine the IQ and the EI of the applicants and can than predict under consideration of experience, how successful they will be in negotiating. Lastly, not only the maximum levels of test performance in all dimensions make a good sales person, but a lack in one dimension can be compensated by another. Being 'perfect' in all test dimensions still does not mean being outstanding in the later sales job.

\section{LIMITATIONS AND AVENUES FOR FUTURE RESEARCH}

The research environment of this study was a lab setting rather a field study. Future research might replicate the study in an even more realistic setting, and might invite sales people to participate. Furthermore, negotiation performance might not be limited to monetary results only. Our approach to select different data sources (test data, objective negotiation results, demographics) helps to secure the findings also beyond suspected common method variance issues. Future research could enrich the set of dependent variables by e.g. behavioural outcomes, relationship oriented outcomes, or strategic outcomes. Lastly, it would be of upmost interest to investigate into dyads of negotiators, e.g. how lower EI/IQ of a buyer interacts with higher EI/IQ of a seller, or vice versa, with respect to negotiation performance.

\section{REFERENCES}

Aiken, L., \& West, S. (1991). Multiple Regression: Testing and Interpreting Interactions. Newbury Park, CA: Sage.

Akers, M., \& Porter, G. L. (2003). Your EQ skills: Got What it Takes? Journal of Accountancy, 195(3), 65-69.

Andersen, P. H., \& Kumar, R. (2006). Emotions, trust and relationship development in business relationships: A conceptual model for buyer-seller dyads. Industrial Marketing Management, $35(4), 522-535$.

Arendasy, M., et al. (2012). Intelligenz-Struktur-Batterie-INSBAT. Mödling: Schuhfried.

Bar-On, R. (2003). Bar-On Emotional Quotient Inventory (Bar-On EQ-i). A Measure of Emotional Intelligence. North Tonawanda: Multi-Health Systems.

Bartkus, K. R., Peterson, M. F., \& Bellenger, D. N. (1989). Type A Behavior, Experience, and Salesperson Performance. Journal of Personal Selling \& Sales Management, 9(2), 11-18.

Becker, G.S. (1962). Investment in human capital: A theoretical analysis. The Journal of Political Economy, 70(5), 9-49. 
Block, N. (1995). On a confusion about a function of consciousness. Behavioral and Brain Sciences, $18(2), 227-247$.

Cacioppo, J. T., \& Gardner, W. L. (1999). Emotion. Annual Review of Psychology, 50(1), 191-214.

Carnevale, P. J. D., \& Isen, A. M. (1986). The influence of positive affect and visual access on the discovery of integrative solutions in bilateral negotiation. Organizational Behavior and Human Decision Processes, 37(1), 1-13.

Cohen, J., \& Cohen, P. (1983). Applied Multiple Regression/Correlation Analysis for the Behavioral Sciences. Hillsdale, NJ: Erlbaum.

Evans, J. (2003). In two minds: dual-process accounts of reasoning. Trends in Cognitive Sciences, 7(10), 454-459.

Epstein, S. (1993). You're smarter than you think: How to develop your practical intelligence for success in living. New York: Simon \& Schuster

Forgas, J. P. (1998). On feeling good and getting your way: Mood effects on negotiator cognition and bargaining strategies. Journal of Personality and Social Psychology, 74(3), 565-577.

Gilligan, C. (1982). Why should a woman be more like a man? Psychology Today, 68-77.

Goleman, D. (1995). Emotional intelligence. Why it can matter more than IQ. New York: Bantam Books, Inc.

Hollingshead, A B., \& Carnevale, P., eds. (1990). Positive Affect and Decision Frame in Integrative Bargaining: A Reversal of the Frame Effect. Academy of Management.

Kidwell, B., Hardesty, D. M., Murtha, B. R., \& Sheng, S. (2011). Emotional Intelligence in Marketing Exchanges. Journal of Marketing, 75(1), 78-95.

Kolb, D. A., Boyatzis, R. E., \& Mainemelis, C. (2011). Experiential Learning Theory: Previous Research and New Directions, in Perspectives on thinking, learning, and cognitive styles. Educational psychology series. New York: Routledge, 227-247.

Lawler, E. J. (2001). An Affect Theory of Social Exchange. American Journal of Sociology, 107(2), 321352.

Lawler, E. J., Thye, S. R., \& Yoon, J. (2000). Emotion and Group Cohesion in Productive Exchange 1. American Journal of Sociology, 106(3), 616-657.

O’Boyle, E. H., Humphrey, R. H., Pollack, J. M., Hawver, T. H., \& Story, P. A. (2011). The relation between emotional intelligence and job performance: A meta-analysis. Journal of Organizational Behavior, 32(5), 788-818.

Petrides, K. V. (2010). Trait Emotional Intelligence Theory. Industrial and Organizational Psychology, 3(2), 136-139.

Petrides, K. V., Pita, R., \& Kokkinaki, F. (2007). The location of trait emotional intelligence in personality factor space. British Journal of Psychology, 98(2), 273-289.

Pruitt, D. G. (2013). Negotiation behaviour. Academic Press.

Quiñones, M. A., Ford, J. K., \& Teachout, M. S. (1995). The relationships between work experience and job performance: A conceptual and meta-analytic review. Personnel Psychology, 48(4), 887-910.

Stone, E., \& Hollenbeck, J. (1989). Clarifying some controversial issues surrounding statistical procedures for detecting moderator variables: empirical evidence and related matters. Journal of Applied Psychology, 74, 3-10.

Stuhlmacher, A. F., \& Walters, A. E. (1999). Gender differences in negotiation outcome: A metaanalysis. Personnel Psychology, 52(3), 653-677.

Thompson, L. L., Wang, J., \& Gunia, B. C. (2010). Negotiation. Annual Review of Psychology, 61, 491515.

Verbeke, W., Belschak, F., Bakker, A., \& Bart, D. (2008). When Intelligence Is (Dys)Functional for Achieving Sales Performance. Journal of Marketing, 72(4), 44-57. 